\title{
A STUDY ON SURGICAL MANAGEMENT OF PROXIMAL HUMERUS FRACTURES BY “PHILOS” PLATE
}

\author{
Tandra Venkateshwara Rao1, Kolipaka Venkataswamy², Jatoth Venkateshwarlu3, Malladi Balaji Varma4
}

1 Professor and HOD, Department of Orthopaedics, Kakatiya Medical College, Warangal, Telangana. ${ }^{2}$ Assistant Professor, Department of Orthopaedics, Kakatiya Medical College, Warangal, Telangana.

3 Professor, Department of Orthopaedics, Kakatiya Medical College, Warangal, Telangana.

${ }^{4}$ Postgraduate Student, Department of Orthopaedics, Kakatiya Medical College, Warangal, Telangana.

\section{ABSTRACT}

\section{BACKGROUND}

Proximal humerus fractures accounts for about $4 \%$ to $5 \%$ of all fractures. They are the third most common fractures in elderly population after hip and distal radius fractures. Due to increasing incidence of high velocity trauma, the fracture pattern in proximal humerus fracture are becoming complicated. It has always been an enigma for the management of such fractures because of numerous muscles attachment and paucity of space for fixing implant in fracture of proximal humerus. The treatment is more controversial for articular fractures, which carry a high risk of the humeral head necrosis. In Neer's classification there are two part anatomical neck, three-part and four-part fracture and those with dislocation of head of humerus. A review of published result suggests that there is no universally accepted form of treatment. Conservative management may be associated with non-union, malunion resulting in painful dysfunction. The object of the osteosynthesis is to reduce the displacement (usually rotation) of each fragment and hold it in place with an implant, the greater tuberosity fragment which has usually been displaced proximally and rotated upward by rotator cuff muscles inserted into it is fixed to the major humeral head fragment, lesser tuberosity fragment similarly displaced by subscapularis is fixed. Three and four part fractures represent $13 \%$ to $16 \%$ of proximal humeral fractures. Treatment options for these displaced fractures include open reduction and fixation. Neer recommended open reduction and internal fixation for displaced two and three parts fractures.

The aim of the present study is this study is undertaken to evaluate the functional outcome and complication of proximal humerus fractures treated by PHILOS locking plate.

\section{MATERIALS AND METHODS}

Prospective study involving Adults (> 18 yrs.) with proximal humerus fractures admitted to MGM Hospital, Warangal, over a period of 2.5 years. In this study period, 30 cases of fractures of proximal humerus were treated by open reduction and internal fixation. PHILOS locking plate were evaluated.

Inclusion Criteria- Two part, three part, four part proximal humeral fractures, acute fracture, age above 18, patient fit for surgery. Exclusion Criteria- Below 18, associated humerus shaft fracture, associated neurovascular injury.

\section{RESULTS}

In our series, majority of the patients were males, elderly aged, with RTA being the commonest mode of injury involving 2 part, 3 part and 4 part fractures of proximal humerus. The fractures united in all 30 patients. Excellent and satisfactory results were found in $80 \%$ of patients with unsatisfactory results in $20 \%$ according to Neer's criteria.

\section{CONCLUSIONS}

In conclusion PHILOS locking plate is an advantageous implant in proximal humeral fractures due to angular stability, particularly in comminuted fractures and in osteoporotic bones in elderly patients, thus allowing early mobilisation and fracture union. The present study was done to evaluate functional outcome and complication following surgical management of proximal humerus fractures treated with PHILOS locking compression plate. From our study, it can be safely recommended that for proximal humerus fractures PHILOS plating is a good choice of surgical treatment.

\section{KEYWORDS}

Humerus, Proximal, Osteoporosis, PHILOS, Neer's Classification, Greater Tuberosity.

HOW TO CITE THIS ARTICLE: Rao TV, Venkataswamy K, Venkateswarlu J, et al. A study on surgical management of proximal humerus fractures by "PHILOS” plate. J. Evolution Med. Dent. Sci. 2017;6(20):1578-1584, DOI: 10.14260/Jemds/2017/347

Financial or Other, Competing Interest: None.

Submission 21-09-2016, Peer Review 23-11-2016,

Acceptance 29-11-2016, Published 09-03-2017.

Corresponding Author:

Dr. Kolipaka Venkataswamy,

Home No. 25-7-186,

Vishnupuri, Kazipet,

Warangal-506003, Telangana.

E-mail: drlathavenkat@gmail.com

DOI: $10.14260 /$ jemds $/ 2017 / 347$

\section{(c) $(7)$}

\section{BACKGROUND}

Proximal humerus fractures are one of the commonest fractures occurring in the human body. They account for approximately $4 \%-5 \%$ of all the fractures.

Incidence of fractures is more common in the elderly, because of decreased bone density. But it can also occur in younger age group following high velocity trauma.

Due to increasing incidence of high velocity trauma, the fracture pattern in proximal humerus fracture are becoming complicated. It has always been an enigma for the management of such fractures, because of numerous muscles attachment and paucity of space for fixing implant in fracture of proximal humerus. The treatment is more controversial for 
articular fractures, which carry a high risk of the humeral head necrosis.

In Neer's classification there are two part anatomical neck, three-part and four-part fracture and those with dislocation of head of humerus. ${ }^{2}$

A review of published result suggests that there is no universally accepted form of treatment.

Conservative management may be associated with nonunion, malunion resulting in painful dysfunction.

The surgery should be carried out as soon as the patient's general condition permit.

A delay of several days makes reduction more difficult and a significant delay results in absorption of bone, making secure internal fixation impossible.

The object of the osteosynthesis is to reduce the displacement (usually rotation) of each fragment and hold it in place with an implant. ${ }^{3}$

Thus, the greater tuberosity fragment which has usually been displaced proximally and rotated upward by rotator cuff muscles inserted into it is fixed to the major humeral head fragment, lesser tuberosity fragment similarly displaced by subscapularis is fixed.

Three and four part fractures represent $13 \%$ to $16 \%$ of proximal humeral fractures. Treatment options for these displaced fractures include open reduction and fixation.

Neer recommended open reduction and internal fixation for displaced two and three part fractures.

Most of the poor results following open reduction and internal fixation of three part fracture are due to imperfect technique. In a three or four part fracture dislocation when the head of the humerus is entirely devoid of any blood supply, it can be replaced by a humeral prosthesis. ${ }^{4}$ However, the goal of proximal humerus fracture fixation should be stable reduction allowing early mobilisation.

This study is conducted to analyse fractures of the proximal humerus that were treated with the PHILOS plate and documents their clinical and functional outcome.

\section{Aims and Objectives}

Aim

To evaluate the functional outcome of proximal humerus fractures treated with PHILOS.

Objectives to evaluate the functional outcome by using Neer's scoring system.

To assess the complications.

\section{Patients and Methods}

Source of the Data: This study is a result of prospective study of 30 cases done in the Department of Orthopaedics, MGM Hospital, Warangal, with proximal humerus fractures between January 2014 and June 2016 at MGM Hospital, Warangal.

Prospective type of study.

\section{Method of Collection of Data}

The study purpose was to include patients with proximal humerus fractures admitted and examined according to protocol and associated injuries were noted.

Clinical and radiological evaluation was done. Fractures classified using Neer's classification. Hb, PCV, TLC, DLC, Blood Sugars, ECG, HIV, HBSAG and HCV carried out to get fitness for surgery.

Patients underwent open reduction internal fixation with
PHILOS plate for the fracture under general anaesthesia/block. Post-operative physiotherapy followed according to protocol to evaluate the functional outcome.

Inclusion Criteria: Two part, three part, four part proximal humeral fractures.

Acute fracture.

Age above 18 patients fit for surgery.

\section{Exclusion Criteria}

Below 18 years, associated humerus shaft fracture, associated neurovascular injury, pathological fractures, old fractures, compound fractures, fracture dislocation of shoulder and chronic cases.

\section{Mechanism of Injury}

1. Fall on outstretched hand with pronated upper extremity - This is a most common cause.

2. Excessive rotation of the arm, especially in abducted position. This has been described by Codman.

3. Direct blow to side of shoulders - may result in greater tuberosity fracture with comminution.

4. A strong externally rotated force when arm is at maximum external rotation and is at about 60 abduction causes lesser tuberosity in fracture.

5. Resisted internal rotation - may cause lesser tuberosity fracture.

Clinical Features: Most of proximal humerus fractures occur as a result of fall usually in elderly with osteoporotic bones. In young patients, it results from high energy trauma.

On examination, there may be extensive ecchymosis and swelling seen, but lacerations and open fractures are rare.

There may be anterior bulge below the corocoid in cases of anterior dislocation.

There may be posterior bulge and anterior sulcus seen in case of posterior dislocation.

On palpation, there will be tenderness around the shoulder and painful movements may be associated with crepitations.

Sensation on lateral aspect of shoulder will give the information about integrity of axillary nerve.

\section{Incidence}

Fractures of proximal humerus comprise approximately $4 \%$ to $5 \%$ of adult fractures, of which $20 \%$ fracture are displaced requiring surgery. In Neer's original series of 300 fractures, the average age of the patients was 55.6 years. Lind found that three-fourth of his patients with proximal humerus fractures were over 60 years. ${ }^{5}$

\section{Classification}

\section{Neer's Classification ${ }^{2}$}

First described in 1970 and then simplified in 1975, was developed from the retrospective review of 300 fractures. Requirements to classify fractures.

Adequate radiographs AP and axillary views and CT Scan for complicated and comminuted fractures and knowledge on the pathology and deforming forces are essential.

Neer set $45^{\circ}$ angulation and $1-\mathrm{cm}$ separation as the thresholds for displacement segment. The four segment classification is based on the presence or absence of displacement of one or more of the four major segments. 


\section{Six Groups were Defined}

Group I includes all fracture, regardless of location or number of fracture lines that have displacement of less than $1 \mathrm{~cm}$ and angulation of less than $45^{\circ}$.

Group II fractures consist of articular segment displacement or anatomical neck fractures. These are rare lesions that can lead to malunion or avascular necrosis.

Group III is composed of surgical neck angulation of greater than $45^{\circ}$. Three subtypes include angulation of greater than $45^{\circ}$. Three subtypes include angulated, separated or unimpacted, and comminuted surgical neck fractures.

Group IV fractures constitute greater tuberosity fractures with displacement of more than $1 \mathrm{~cm}$ from the lesser tuberosity. This fracture pattern is pathognomonic of a rotator cuff tear.

Group V is composed of displaced lesser tuberosity fractures that occur as isolated avulsion fractures, such as after a seizure or in association with a non-displaced surgical neck fracture.

Group VI consists of fracture dislocations, either anterior or posterior including impression fractures.

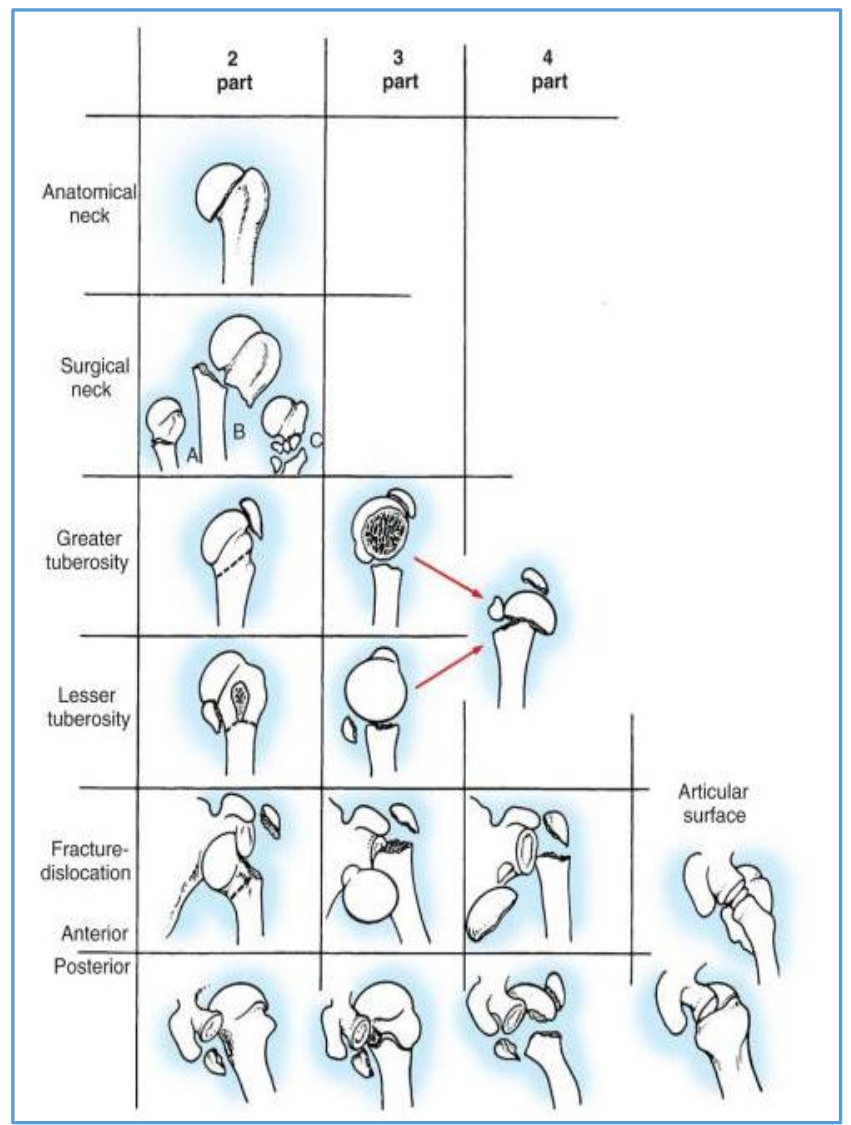

\section{Surgical Approach 6}

Deltopectoral approach was used in all cases.

Procedure: Incision starts just above the coracoid process, plane runs between the deltoid muscle and the pectoralis major muscle. The fracture was exposed and reduced anatomically and fixed temporarily with $\mathrm{K}$ wires. In case of obvious rotation or displacement of the humeral head, a joystick technique was used. Then the shaft fragment was reduced by abduction, traction and rotation of the arm. Definitive fixation with PHILOS plate was done after satisfactory reduction was achieved under C-arm guidance. Secure the tendons of the rotator cuff (subscapularis, supraspinatus, infraspinatus) with additional tension band sutures through the small holes in the plate. The screws were chosen according to preoperative planning and all the four head screws were supposed to be inserted to the head fragment. The inferior screws supporting the humeral head were considered critical. Proximal locking screws were inserted to hold the humeral head, which are multidirectional screws with the tips of the screws staying $5-10 \mathrm{~mm}$ away from the articular surface.

\section{Draping of surgical site}

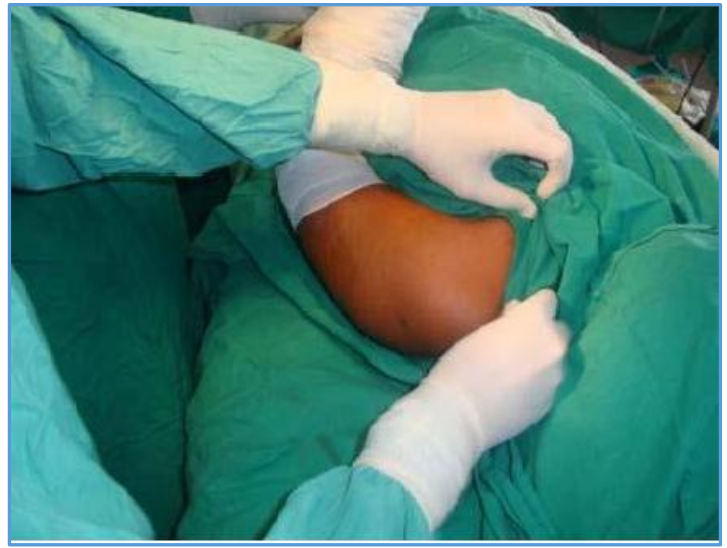

Skin incision through Deltopectoral approach

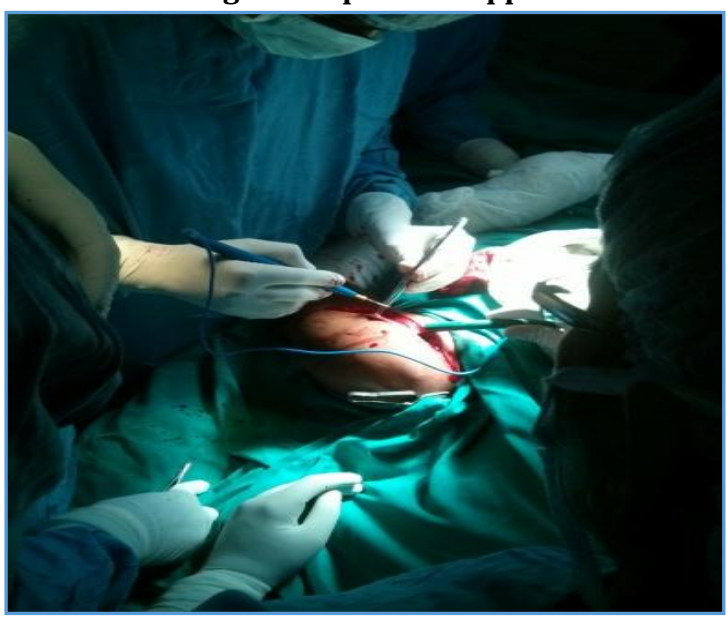

Provisional fixation of fracture with K-Wires

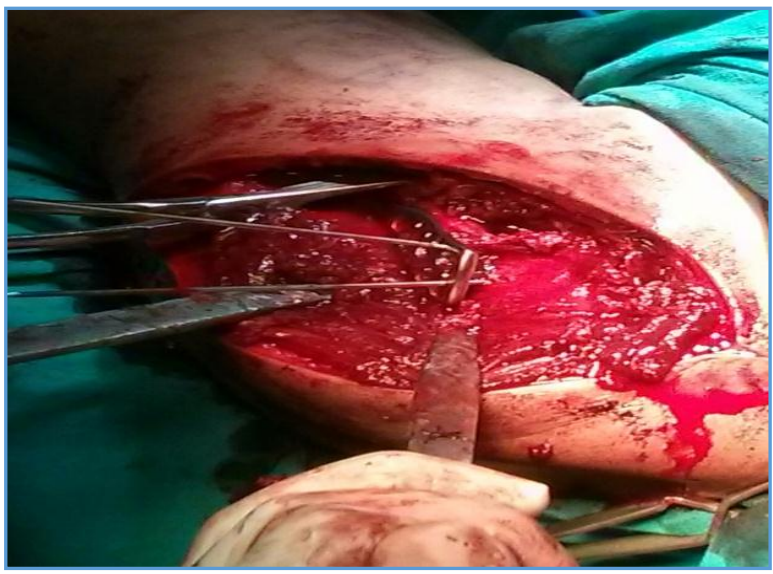




\section{Final fixation of PHILOS Plate}

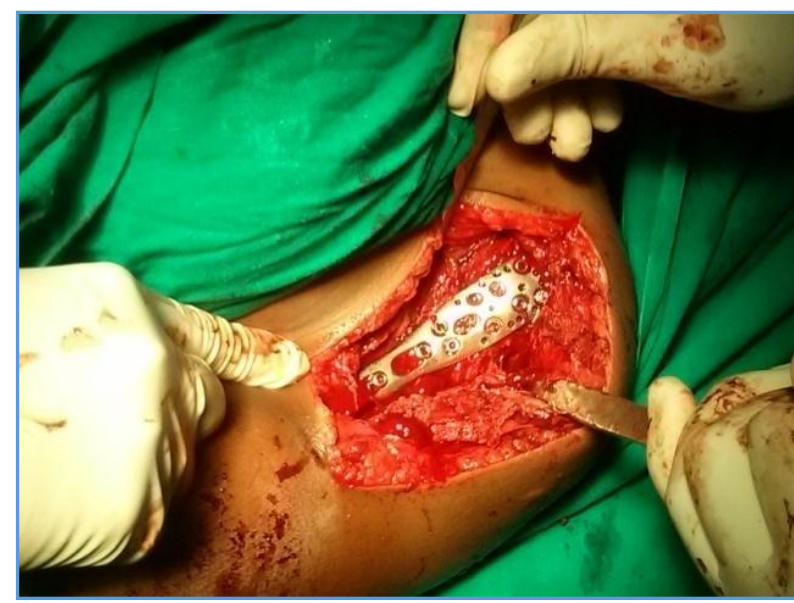

Postoperative Management

All patients are immobilised in shoulder immobilizer. Appropriate antibiotics (3rd generation cephalosporin) and analgesics were used. Immediate post-operative radiographs were taken to determine the bone alignment and maintenance of reduction. Sutures removed by 12 th day.

\section{Rehabilitation ${ }^{7}$}

Pendulum exercises are begun immediately depending on pain tolerance. Passive range of motion started at 1st week, the active range of motion was started at $2-4$ weeks postoperatively depending on stability of osteosynthesis and bone quality; 4th to 6th week-immobilisation discontinued. Active assisted movements started up to $90^{\circ}$ abduction with no forced external rotation; 6th to 8th week - full range of movements with active exercises started.

\section{Follow-up}

At each followup patients were examined clinically and radiologically, assessed for range of motion and bony union and any complications.

Further followups were done at 6 weeks and 12 weeks and 24 weeks.

The final results were evaluated at the end of 12 months by using the Neer's scoring system.

The patient with shoulder stiffness were given physiotherapy for 1 week to 15 days on outpatient basis.

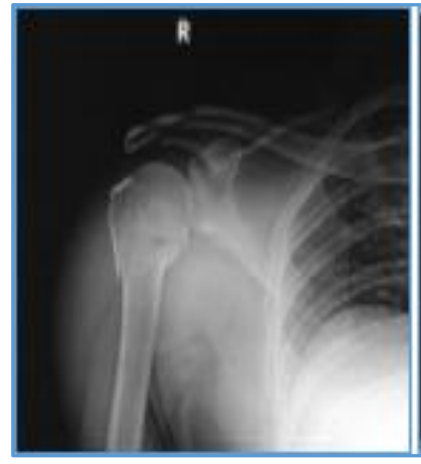

Pre-Op X-Ray

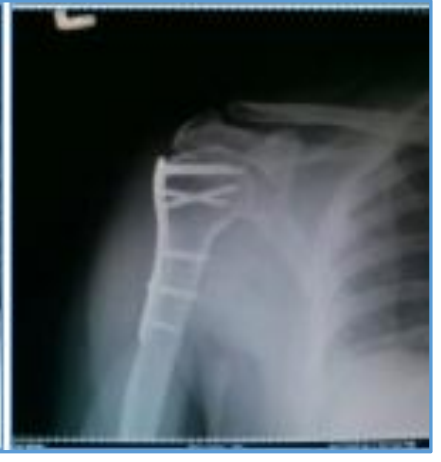

Follow-Up X-Ray

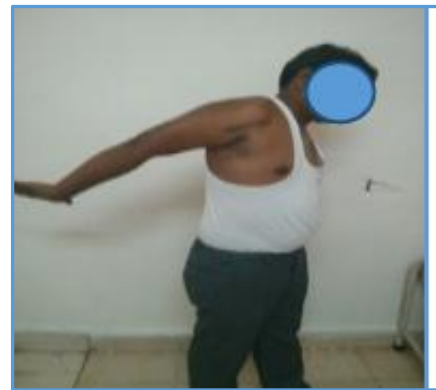

EXTENSION

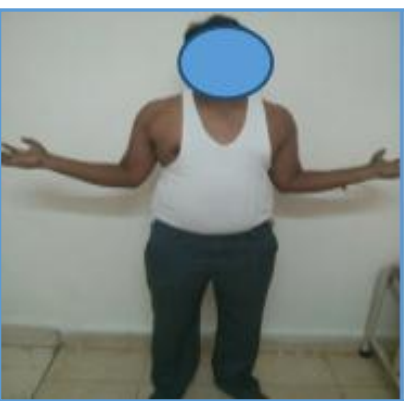

EXTERNAL ROTATION

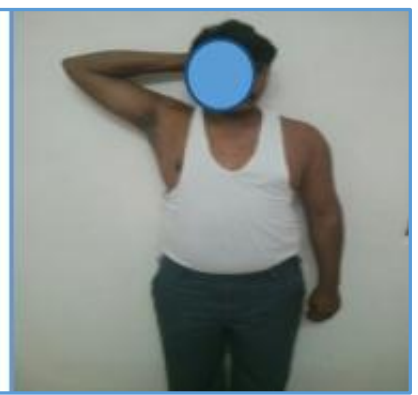

ABDUCTION

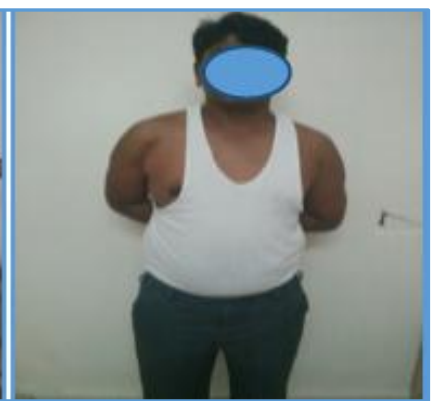

INTERNAL ROTATION

\section{RESULTS}

Result assessment as per Neer's Criteria at the end of 12 months followup $(n=30)$

The Neer's scoring system of the severity of pain, function, range of movements and anatomy was done to determine the end results. Thirty patients with closed displaced proximal humerus fracture were treated by open reduction with locking compression plate. The following observations were made from the data collected during this study.

\begin{tabular}{|c|c|c|}
\hline Age in Years & No. of Patients & Percentage \\
\hline $18-37$ & 3 & 10 \\
\hline $38-57$ & 9 & 30 \\
\hline $58-77$ & 18 & 60 \\
\hline \multicolumn{3}{|c|}{ Table 1. Age Distribution } \\
\hline
\end{tabular}

Majority of the patients, i.e. $18(60 \%)$ were from age group of 58 - 77 years followed by 9 patients (30\%) in $38-57$ age group. The average age of patient was 53.7 years. Majority of the patient in our group are elderly in our study.

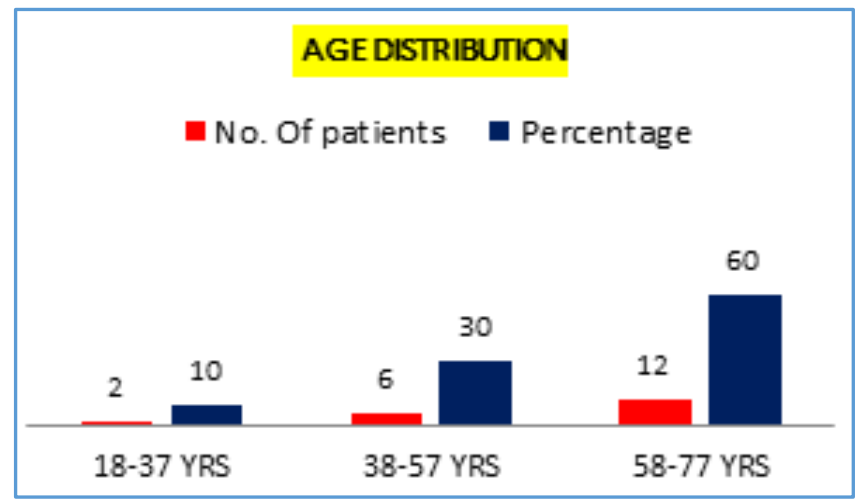

Graph 1. Age Distribution 


\begin{tabular}{|c|c|c|}
\hline Sex & No. of Patients & Percentage \\
\hline Male & 18 & 60 \\
\hline Female & 12 & 40 \\
\hline \multicolumn{2}{|c|}{ Table 2. Sex Distribution } \\
\hline
\end{tabular}

Majority of the patients were males, i.e. $60 \%$ and $40 \%$ were females. Male:Female sex ratio is 3:2.

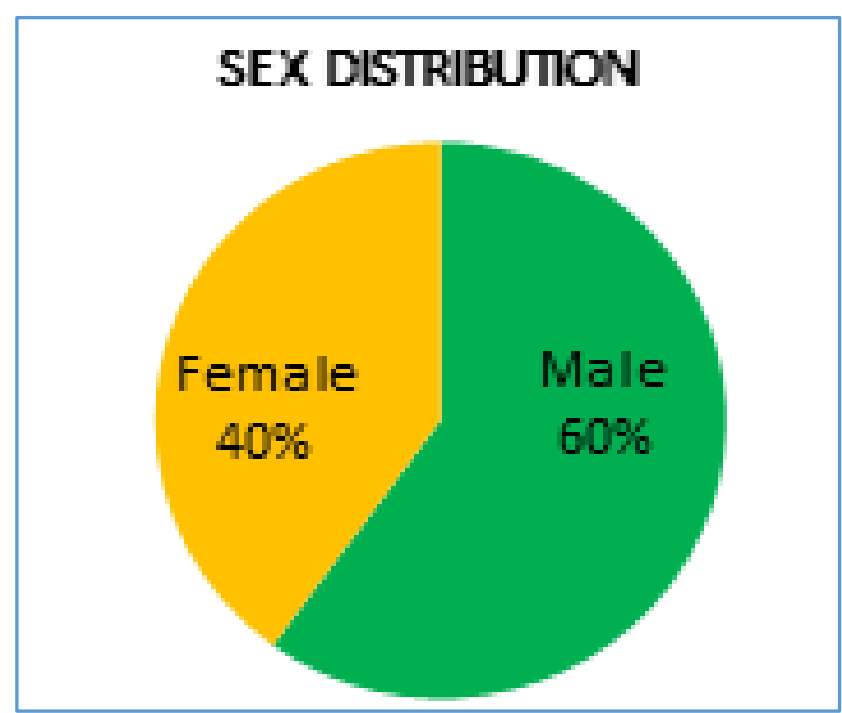

Graph 2. Sex Distribution

\begin{tabular}{|c|c|c|}
\hline Nature of Trauma & No. of Patients & Percentage \\
\hline Road Traffic Accident & 21 & 70 \\
\hline Fall Table 3. Mode of Injury \\
\hline \multicolumn{2}{|c|}{} \\
\hline
\end{tabular}

In majority (70\%) cases, the mode of injury was RTA. This included high energy trauma directly or indirectly to shoulder.

The injury from fall ( $30 \%$ of cases) was due to fall from steps or from the bicycle on outstretched hand.

\section{PIE Diagram Shows Type of Injury}

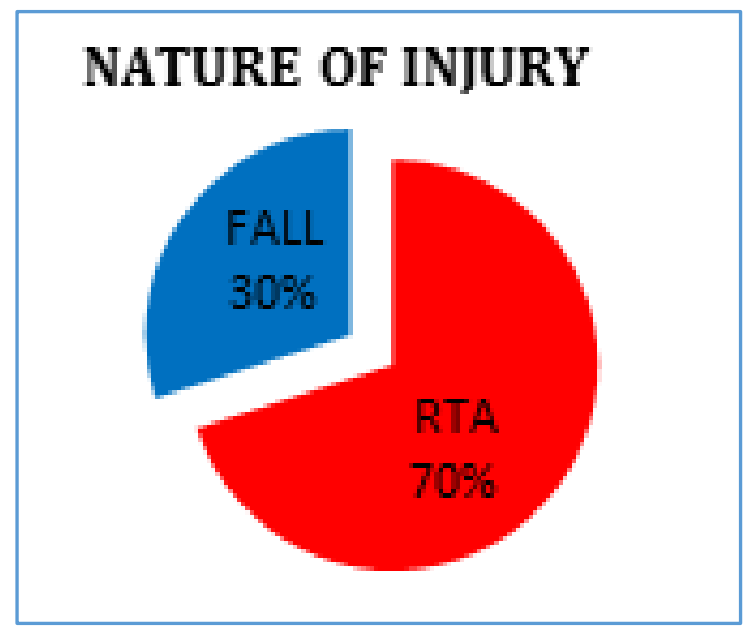

\begin{tabular}{|c|c|c|}
\hline Side & No. of Patients & Percentage \\
\hline Right & 21 & 70 \\
\hline Left & 9 & 30 \\
\hline \multicolumn{2}{|c|}{ Table 4. Side Affected } \\
\hline
\end{tabular}

The fracture occurred right in 21 patients $(70 \%)$ and left side in 9 patients (30\%).

\section{Picture shows that Side of Affection}

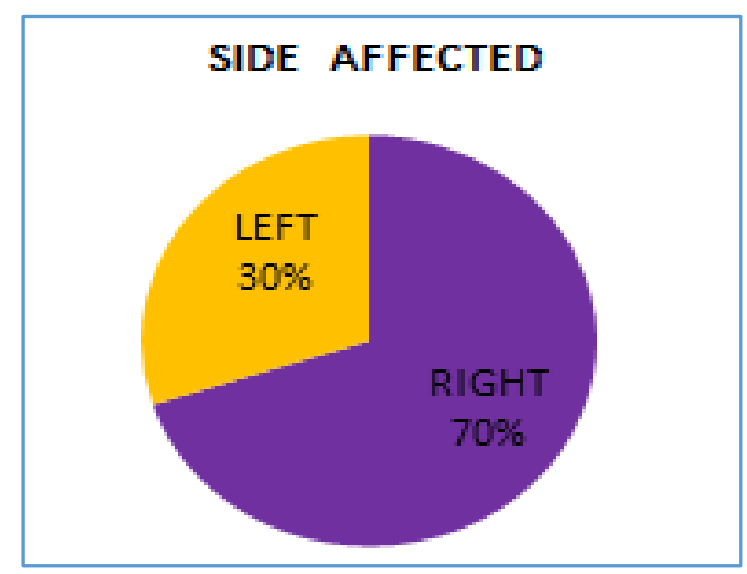

\begin{tabular}{|c|c|c|}
\hline Fracture Pattern & $\begin{array}{c}\text { No. of } \\
\text { Patients }\end{array}$ & Percentage \\
\hline 2 part (surgical neck) & 12 & 40 \\
\hline $\begin{array}{c}3 \text { part (surgical neck + } \\
\text { greater tuberosity) }\end{array}$ & 9 & 30 \\
\hline $\begin{array}{c}3 \text { part (surgical neck }+ \\
\text { lesser tuberosity) }\end{array}$ & 3 & 10 \\
\hline 4 Part & 6 & 20 \\
\hline
\end{tabular}

In our study, we had 12 cases (40\%) with 2 part fracture surgical neck humerus and $9(30 \%)$ cases with 3 part (greater tuberosity and surgical neck) fractures; $3(10 \%)$ case with 3 part (lesser tuberosity and surgical neck); 6 (20\%) cases with 4 part fractures.

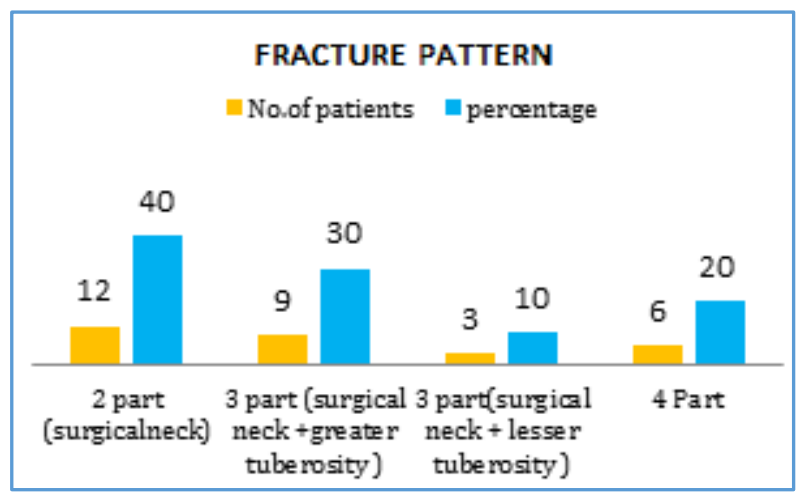

\section{Method of Treatment}

All patients underwent open reduction and internal fixation with PHILOS locking plate.

Time of Surgery: The average interval between fracture and surgery was 3.55 days.

Stay in Hospital: The average hospital stay in our study was 9.5 days. 


\begin{tabular}{|c|c|c|}
\hline Complication & No. of Patients & Percentage \\
\hline Impingement & 3 & 10 \\
\hline Varus Malunion & 2 & 6.75 \\
Stiffness & 6 & 20 \\
\hline \multicolumn{2}{|c|}{ Table 6. Complications } \\
\hline
\end{tabular}

PIE Diagram Shows Post-0p Complications

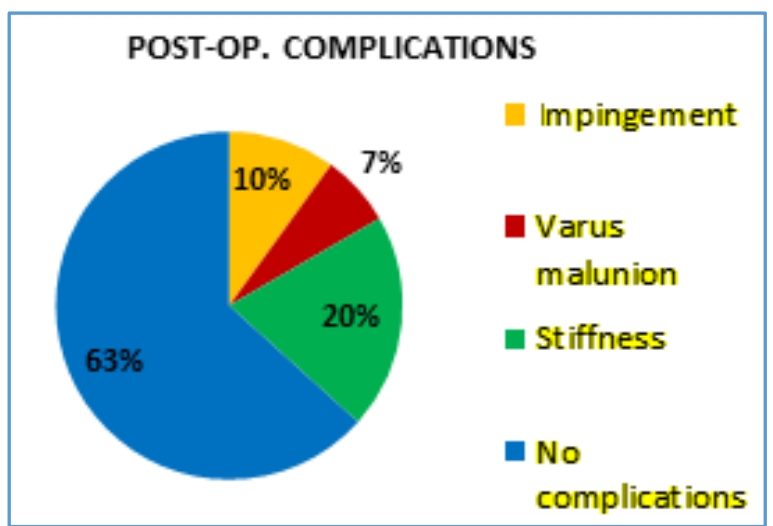

Impingement of the implant with restriction of movements was present in $3(10 \%)$ of cases. There were 2 $(6.75 \%)$ cases with varus malunion, but both patients had comparatively good functional range of movements. Stiffness is seen in 6 cases $(20 \%)$, it was due to poor compliance of patients for physiotherapy.

We had 2 cases of secondary displacement and malunion and 3 cases of plate impingement. Secondary displacement and malunion occurred in two cases at surgical neck. It usually involves to anterior angulation and varus deformity, decreasing neck shaft angle $<120$. In both the cases, it was probably due to comminution of underlying osteoporotic bone, which may have impaction at the fracture site after reduction leading to varus malunion. Three patients had plate impingement and limitation of abduction. Its hardware related complication, improper plate positioning may have led to impingement.

\section{Functional Results}

All fractures united by 6 - 8 weeks interval. The final results were evaluated by Neer's scoring criteria.

\begin{tabular}{|c|c|c|}
\hline Grade & No. of Patients & Percentage \\
\hline Excellent & 6 & 20 \\
\hline Satisfactory & 18 & 60 \\
\hline Unsatisfactory & 6 & 20 \\
\hline \multicolumn{2}{|c|}{ Table 7. Results According to Neer's Criteria } \\
\hline
\end{tabular}

In our study 6 (20\%) cases had excellent results and 18 $(60 \%)$ had satisfactory result; $6(20 \%)$ had unsatisfactory result and there was no case of failure.

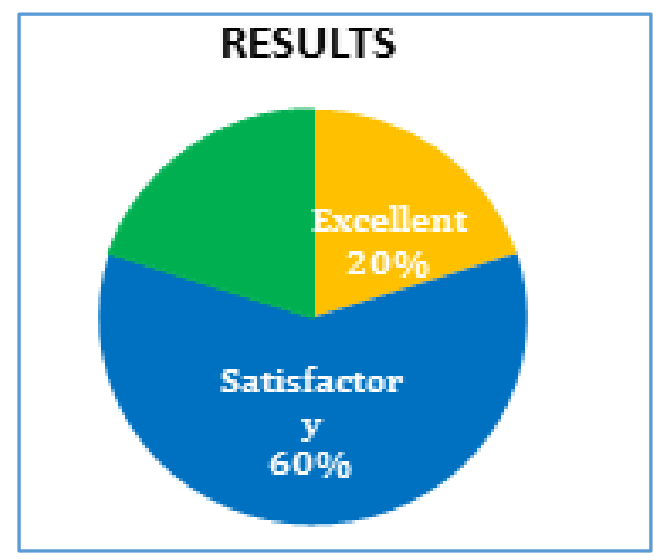

\begin{tabular}{|c|c|c|}
\hline Movements & Range & Average \\
\hline Flexion & $130-180^{\circ}$ & $166.25^{\circ}$ \\
\hline Extension & $30-45^{\circ}$ & $42.2^{0}$ \\
\hline Abduction & $110^{0}-180$ & $152.5^{\circ}$ \\
\hline External rotation & $30-60^{\circ}$ & $48.75^{\circ}$ \\
\hline Internal rotation & $60-90^{\circ}$ & $73.75^{\circ}$ \\
\hline
\end{tabular}

Table 8. Range of Movements in Excellent and Satisfactory Results

We had unsatisfactory results in $6(20 \%)$ patients. The unsatisfactory cases, out of 3 plate impingement cases 1 case had good functional range of movement with minimal pain, which was considered as satisfactory. Other 2 impingement cases had restriction of abduction $<90^{\circ}$, which was considered as unsatisfactory; 2 more cases developed varus malunion with restriction of movements and with persistent mild-to-moderate pain, which considered as unsatisfactory; 6 patients with unsatisfactory results had fair-to-good muscle function, limitation of movements with mild-to-moderate pain; with these functions they were considered unsatisfactory according to Neer's criteria.

\begin{tabular}{|c|c|c|}
\hline Movements & Range & Average \\
\hline Flexion & $100-140^{\circ}$ & $115^{\circ}$ \\
\hline Extension & $30-45^{\circ}$ & $40^{\circ}$ \\
\hline Abduction & $100^{\circ}-110$ & $107.5^{\circ}$ \\
\hline External rotation & $30-45^{\circ}$ & $37.5^{\circ}$ \\
\hline Internal rotation & $50-60^{\circ}$ & $55^{\circ}$ \\
\hline Table 9. Range of Movements in Unsatisfactory Results \\
\hline
\end{tabular}

All fracture united by 3 months on an average of 10 weeks (8 to 12 weeks). There were no case of failure in our study. In comparison to other study on surgical management of proximal humerus, we had similar results. Our studies in comparison with studies conducted by Hong-Fei Shi et al ${ }^{8}$ and Ramchander Siwach et al, ${ }^{9}$ which are similar to our study group. All three study groups came up with similar results, although avascular necrosis, screw penetration and loosening of implant ${ }^{10}$ were not seen in our group.

\section{DISCUSSION}

The operative treatment of proximal humeral fractures provides orthopaedician with a therapeutic challenge.

Most of the proximal humerus fractures, which are nondisplaced can be treated conservatively.

Even if the injury is thoroughly analysed and the literature is understood, treatment of displaced fracture or fracture dislocation is difficult. ${ }^{11}$

The result is related to restoration of anatomical alignment and if fracture is treated only with rest followed by early motion, a functional deficit will certainly develop and may be associated with pain. The external support is difficult to apply effectively, because fracture site is adjacent to trunk.

Many studies have shown that the displaced fracture of the proximal humerus have a poor functional prognosis when left untreated, because of severe displacement of fragments.

Numerous investigators have described the various surgical treatment for displaced proximal humerus fracture. There is no consensus on optimal treatment of displaced proximal humeral fractures, which account for about $20 \%$ of fractures.

In some studies, the objective functional results of conservative treatment have been unsatisfactory. The fractures are defined by variety of classification systems. The 
difficulty in accurately classifying the fracture creates problems in reporting outcome and also none of the system gives clear prognosis and direction of treatment. Overall, open reduction and internal fixation, although not in all institution have yielded satisfactory results. The best results are obtained if the fracture is well reduced and planned rehabilitation program followed. It must be the goal to select fractures for open reduction and internal fixation, which can be anatomically reduced. This is dependent on various factors such as type of fracture, the quality of the bone and the technique of reduction and fixation. The present study was conducted to assess the results of two part, three part and four proximal humeral fracture treated by open reduction internal fixation by PHILOS locking plate.

\section{CONCLUSION}

The present study was done to evaluate functional outcome and complication following surgical management of proximal humerus fracture by PHILOS locking plate.

Proximal humerus fracture is common in elderly, aged patients in our study. The commonest mode of injury is RTA. Accidental fall is next common mode of injury.

Proximal Humeral Internal Locking system (PHILOS). In this system, locking of the threaded heads of the screws in the plate itself provides for a construct with angular and axial stability, eliminating the possibility of screw toggling (windscreen wiper effect) or sliding of the screws in the plate holes. Coupled with a divergent or convergent screw orientation, this makes for much improved resistance to pull out and failure of fixation. Also, whereas conventional plating systems depend on compression between the plate undersurface and bone for stability; this is not the case for the PHILOS.

This lessens the chance of stripping the thread in osteoporotic bone, as the plate/bone interface is not loaded along the screw axis. This also allows for a more biological fixation as the underlying periosteum and blood supply to the fractured regions are much less compressed. The most common complication in open reduction and plate fixation is plate impingement, leading to limitation of abduction. The surgical management of proximal humerus fracture is demanding. Results are best when the operative method results in stable fixation. Fixation should be followed by early physiotherapy.

The rehabilitation programme plays important role in functional outcome of surgical management of proximal humerus fracture. In conclusion PHILOS locking plate is an advantageous implant in proximal humeral fractures due to angular stability, particularly in comminuted fractures and in osteoporotic bones in elderly patients, thus allowing early mobilisation.

\section{Summary}

Thirty displaced 2 part, 3 part and 4 part proximal humerus fracture were treated surgically by open reduction and internal fixation between January 2014 and June 2016 at MGM Hospital, Warangal.

In our study, patients were aged between 18 - 77 years. The average age of the patients in our study was 53.7 years and maximum number of patients were between $58-77$ years of age.

In our study, $18(60 \%)$ were males and $12(40 \%)$ were females. The fracture occurred on left side in 9 patients (30\%) and right side in 21 patients (70\%).

All fractures united around 8 - 12 weeks (mean 10 weeks) in our study. Complication includes 2 cases of varus malunion, 3 cases of plate impingement and 6 cases of stiffness. Our study did not encounter any other complications like avascular necrosis, screw penetration or loosening of implant. The final results were evaluated by Neer's criteria. In our study, $80 \%$ of patients had good-toexcellent result and $20 \%$ with unsatisfactory results. There were no cases of failure.

\section{REFERENCES}

[1] Lind T, Kroner K, Jensen J. The epidemiology of fractures of proximal humerus. Arch Orthop Trauma Surg 1989;108(5):285-7.

[2] Neer CS. Dispalced proximal humeral fracture. 1. Classification and evaluation. J Bone Joint Surg (Am) 1970;52(6):1077-89.

[3] Thyagarajan DS, Haridas SJ, Jones D, et al. Functional outcome following proximal humeral interlocking system plating for displaced proximal humeral fractures. Int J Shoulder Surg 2009;3(3):57-62.

[4] Antuña SA, Sperling JW, Cofield RH. Shoulder hemiarthroplasty for acute fractures of the proximal humerus: aminimum five year follow-up. J Shoulder Elbow Surg 2008;17(2):202-9.

[5] Bell JE, Leung BC, Spratt KF, et al. Trends and variation in incidence, surgical treatment, and repeat surgery of proximal humeral fractures in the elderly. J Bone Joint Surg Am 2011;93(2):121-31.

[6] Stanley Hoppenfield Operative exposure. $4^{\text {th }}$ edn. page 4-15.

[7] Rosén, Kajsa, RPT. Physiotherapeutic interventions and rehabilitation regimen of the surgically stabilized proximal humeral fracture - a literature review. 2010:134.

[8] Shi HF, Xiong J, Chen YX, et al. Management of proximal humeral fractures in elderly patients with uni-or polyaxial locking osteosynthesis system. Arch Orthop Trauma Surg 2011;131(4):541-7.

[9] Siwach R, Singh R, Rohilla RK, et al. Internal fixation of proximal humerus fracture by locking proximal humerus plate in elderly osteoporotic. J Orthopaed Traumatol 2008;9(3):149-53.

[10] Owsley KC, Gorczyca JT. Fracture displacement and Screw Cutout after open reduction and locked plate fixation of proximal humeral fractures. J Bone Joint Surg Am 2008;90(2):233-40.

[11] Koukakis A, Apostolou CD, Taneja T, Korres DS, Amini A. Fixation of proximal humerus fractures using the PHILOS plate: early experience. Clin Orthop Relat Res 2006;442:115-20. 